\section{Children with sickle cell anemia and APOL1 genetic variants develop albuminuria early in life}

Individuals with sickle cell anemia (SCA) often have kidney damage. Approximately $25 \%$ of infants exhibit hyposthenuria, $10-30 \%$ of adolescents progress to albuminuria, and up to $20 \%$ of adults have albuminuria and progressive renal insufficiency, defined as a creatinine clearance of $<90 \mathrm{~mL} / \mathrm{min}$, or chronic kidney disease (CKD). ${ }^{1}$ Individuals with SCA and CKD frequently progress to end stage renal disease (ESRD) and require dialysis or transplant; however, individuals with SCA have a worse survival and are less likely to receive a kidney transplant compared to African Americans with ESRD who do not have SCA..$^{2,3}$ One approach to improve clinical outcomes for individuals with SCA is to identify those at high risk of developing ESRD and initiate renoprotective medical therapies early; these include angiotensin-converting-enzyme (ACE) therapy which is beneficial for individuals with and without SCA, ${ }^{4,5}$ and hydroxyurea (HU) which is beneficial for individuals with SCA who have advanced renal damage. , $^{6,7}$

Albuminuria is an accurate early marker of renal damage, ${ }^{2}$ and the National Heart Lung and Blood Institute (NHLBI) guidelines for SCA recommend screening for albuminuria beginning at ten years of age for all patients; however, genetic information may allow earlier identification of those at risk for ESRD and thereby influence therapeutic decisions. There are two common variants in the apolipoprotein L-1 (APOL1) gene that confer increased risk for kidney disease in a variety of clinical circumstances and accelerate kidney damage synergistically with numerous other comorbid medical conditions. ${ }^{8-13}$ Variant G1 is comprised of two strongly linked missense mutations: rs73885319 (p.S342G) and rs60910145 (p.I384M). Variant G2 is a 6 base pair (bp) inframe deletion (rs71785313, N388del:Y389del). These variants are enriched in African populations due to evolutionary selective pressure for resistance to trypanosomiasis, ${ }^{8,9}$ similar to the enrichment of sickle cell disease (SS) due to resistance to malaria, and cross-sectional studies of SCA cohorts have associated APOL1 risk alleles with albuminuria. ${ }^{10,14,15}$ However, the effects of these APOL1 variants on the age of onset of albuminuria and the rate of progression to CKD over time are not known. Understanding how genetic risk factors influence the progression of SCA-associated kidney disease is essential for identifying individuals who would benefit most from early therapeutic intervention.

The Sickle Cell Clinical Research and Intervention Program (SCCRIP; clinicaltrials.gov identifier: 02098863) ${ }^{16}$ is a lifetime longitudinal study that assesses organ function and couples that phenotypic information with whole genome sequencing (WGS). We tested the hypothesis that APOL1 G1 and G2 variant alleles confer an increased risk for kidney damage, evidenced by albuminuria, in young children with SCA followed longitudinally from birth in the SCCRIP cohort.

We analyzed WGS data by aligning paired-end $150 \mathrm{bp}$ reads to the GRCh38 human reference using the Burrows-Wheeler Aligner (BWA-ALN v0.7.12) to achieve

Table 1. Characteristics of patients and genetic association results for APOL1 variants with albuminuria.

\begin{tabular}{|c|c|c|c|c|c|}
\hline & $\begin{array}{l}\text { Time to } \\
\text { event } \\
\text { analysis }\end{array}$ & & case-contro & & P* \\
\hline $\begin{array}{l}\text { Gender } \\
\text { Male } \\
\text { Female }\end{array}$ & $\begin{array}{c}\text { All patients } \\
149 \\
142\end{array}$ & $\begin{array}{l}\text { Albuminuria } \\
16 \\
28\end{array}$ & $\begin{array}{l}\text { Control } \\
16 \\
28\end{array}$ & $\begin{array}{l}\text { All patients } \\
32 \\
56\end{array}$ & $\mathrm{n} / \mathrm{a}$ \\
\hline $\begin{array}{l}\text { Age } \\
\text { Mean(SD) }\end{array}$ & $11.52(4.64)$ & $10.41(3.67)$ & $10.61(3.89)$ & $10.51(3.76)$ & 0.1 \\
\hline $\begin{array}{l}\text { Beta globin genotype } \\
\text { HbSS } \\
\text { HbSB0 }\end{array}$ & $\begin{array}{c}272 \\
19\end{array}$ & $\begin{array}{c}44 \\
0\end{array}$ & $\begin{array}{c}44 \\
0\end{array}$ & $\begin{array}{c}88 \\
0\end{array}$ & $\mathrm{n} / \mathrm{a}$ \\
\hline $\begin{array}{l}\text { HU (ever/never) } \\
\text { Yes } \\
\text { No }\end{array}$ & $\begin{array}{c}197 \\
94\end{array}$ & $\begin{array}{c}35 \\
9\end{array}$ & $\begin{array}{c}35 \\
9\end{array}$ & $\begin{array}{l}70 \\
18\end{array}$ & $n / a$ \\
\hline $\begin{array}{l}\text { RS6090145 / RS73885319 (G1) } \\
\text { Mutant } \\
\text { WT }\end{array}$ & $\begin{array}{l}106 \\
185\end{array}$ & $\begin{array}{l}19 \\
25\end{array}$ & $\begin{array}{l}10 \\
34\end{array}$ & $\begin{array}{l}29 \\
59\end{array}$ & 0.07 \\
\hline $\begin{array}{l}\text { RS71785313 (G2) } \\
\text { Mutant } \\
\text { WT }\end{array}$ & $\begin{array}{c}90 \\
201\end{array}$ & $\begin{array}{l}17 \\
27\end{array}$ & $\begin{array}{l}15 \\
29 \\
\end{array}$ & $\begin{array}{l}32 \\
56\end{array}$ & 0.7 \\
\hline $\begin{array}{l}\text { APOL1 G1/G2 heterozygotes } \\
\text { Yes } \\
\text { No }\end{array}$ & $\begin{array}{c}17 \\
274\end{array}$ & $\begin{array}{c}4 \\
40\end{array}$ & $\begin{array}{c}1 \\
43\end{array}$ & $\begin{array}{c}5 \\
83\end{array}$ & 0.22 \\
\hline $\begin{array}{l}\text { APOL1 G1/G2 Risk Model } \\
\text { Yes } \\
\text { No }\end{array}$ & $\begin{array}{c}32 \\
259\end{array}$ & $\begin{array}{l}11 \\
33\end{array}$ & $\begin{array}{c}1 \\
43\end{array}$ & $\begin{array}{l}12 \\
76\end{array}$ & 0.02 \\
\hline Total & 291 & 44 & 44 & 88 & $\mathrm{n} / \mathrm{a}$ \\
\hline
\end{tabular}

*Conditional logistic regression matched by sex, age, $\beta$-globin genotype, and "ever"/"never" on hydroxyurea. Mutant: presence of one or more copies of the alternative allele. 'APOL1 G1/G2 heterozygotes defined as rs71785313="TTATAA/-" and rs6090145="AG" or rs71785313="TTATAA/-" and rs73885319="AG". ₹APOL1 G1/G2 Risk Model-defined risk variant as G1 or G2 homozygotes or G1/G2 heterozygotes. 


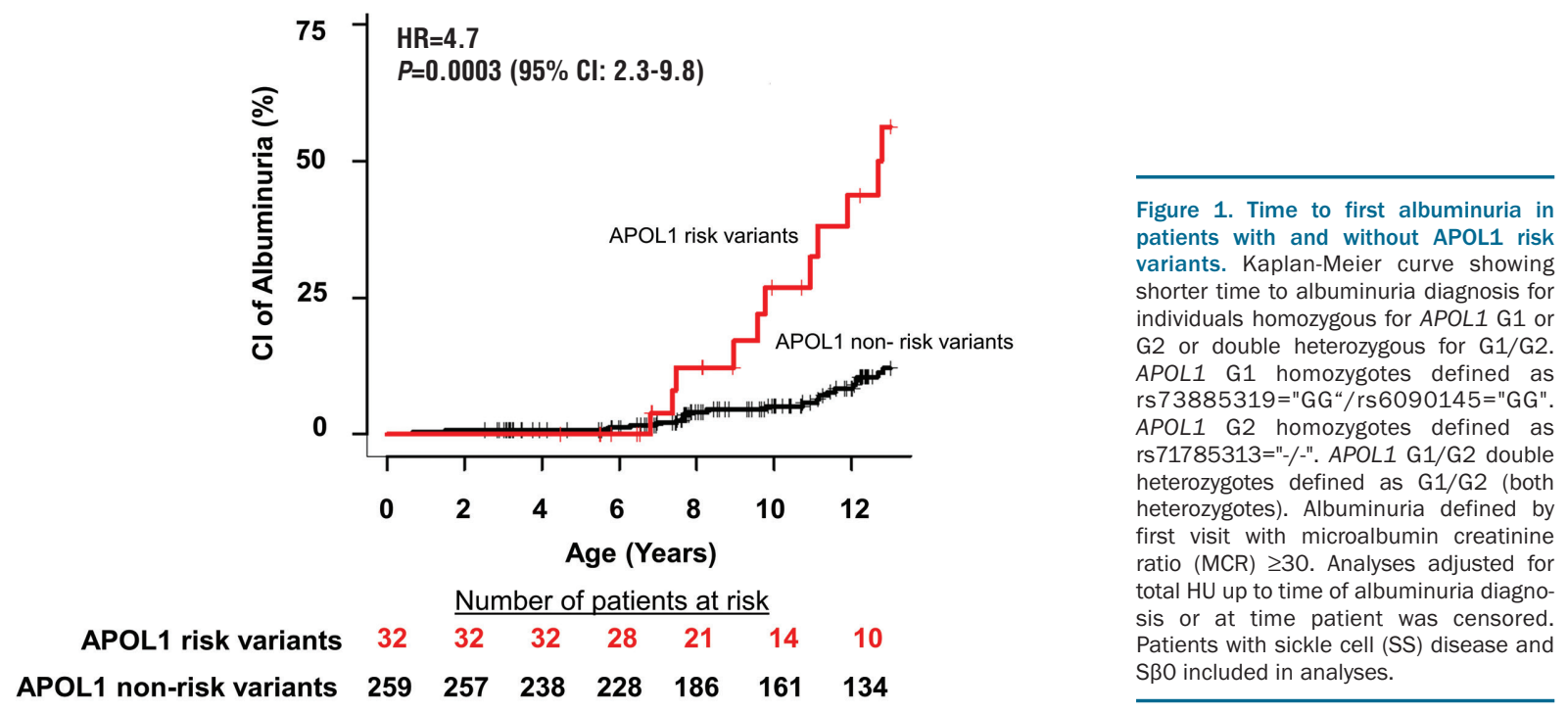

$30 \mathrm{x}$ average coverage. Genetic variants in all patients were then determined by the GATK best-practices workflow (GATK v3.4.0), and APOL1 G1 (rs73885319/rs6090145) and G2 (rs71785313) variants were extracted. In addition to testing each $A P O L 1$ variant individually, we also considered a model in which we defined high-risk APOL1 mutations as either APOL1 G1 or $\mathrm{G} 2$ homozygotes, or G1/G2 double heterozygotes. We used matched case-control analysis to associate APOL1 variants with albuminuria versus controls using conditional logistic regression models matched by sex, age, and $H B B$ genotype. Further, time-to-albuminuria analyses, defined by urine albumin:creatinine ratio (ACR) $>30 \mathrm{mg} / \mathrm{g}$, were conducted using the Weibull parametric survival regression model accommodating left, right, and interval censored data. Participants were censored at 13 years old for the time-to-event analysis due to sparse date. Survival analyses were adjusted for time spent on $\mathrm{HU}$ therapy. All statistical analyses were performed using SAS V9.4. (Cary, NC, USA) and R-3.2.5.

We analyzed 291 participants with SCA ( $n=272 \mathrm{HbSS}$, $19 \mathrm{HbS} \beta 0$ thalassemia) for APOL1 risk variants and ACR. The mean age at the time of the most recent urine ACR measurement was $11.5 \pm 4.76$ years old. Among 175 participants $\geq 10$ years, $22 \%$ of participants developed albuminuria; all had HbSS genotype.

We performed a 1:1 matched case-control analyses of patients with and without albuminuria, controlling for sex, age, $\beta$-globin genotype, and "ever"/"never" on HU. Consistent with previous findings, homozygosity for either G1 or G2 or compound G1/G2 heterozygosity were associated with albuminuria $(P=0.0217)$ (Table 1$)$. In contrast, we have not yet identified an association between $\alpha$-thalassemia genotypes on the development of albuminuria in this young cohort $(\mathrm{HR}=0.723,95 \% \mathrm{CI}$ : $0.406-1.289 ; P=0.2713)$. Next, to test the impact of $A P O L 1$ high-risk variants on time to develop albuminuria, we performed survival analysis. Multivariate survival analyses showed that the time to develop first albuminuria was shortened by $41 \%$ [event time ratio estimate, 0.59; 95\% Confidence Interval (CI): 0.44-0.79] for individuals with high-risk APOL1 variant combinations $\left(P=3 \times 10^{-4}\right)$ (Figure 1). Also, every one year increment in time spent on $\mathrm{HU}$ treatment $(P=0.01)^{16}$ was correlated with a $7 \%$ (event:time ratio estimate, 1.07; 95\%CI: 1.011.13) delay in time to first albuminuria. Double heterozygotes had an event:time ratio estimate of $0.74(95 \% \mathrm{CI}$ : 0.51-1.07; $P=0.11)$ after adjusting for time on HU treatment (data not shown).

Prior studies showed that APOL1 risk alleles confer increased risk for albuminuria in older individuals with SCA, which heralds future CKD., ${ }^{7,10}, 12$ Our data provide novel evidence that $A P O L 1$ risk alleles predict earlier onset of albuminuria in young children, even prior to the recommended screening timelines from current guidelines. In contrast, $\alpha$-thalassemia, which has been shown to be protective against the development of albuminuria in adults with SS, has not yet been identified as a significant risk factor for the development of albuminuria in this younger cohort. Thus, APOL1 screening of children with SS is likely to identify those at high risk for development of albuminuria and those at risk of developing early $\mathrm{CKD}$. These individuals may benefit from $\mathrm{HU}$ or renoprotective therapies prior to the onset of albuminuria, when glomerular damage has already begun.

Limitations of this study include the young age of the cohort, relatively small sample size, and short follow-up time. These limitations reduced our ability to assess other risk variables including concomitant therapies, total hemoglobin level, fetal hemoglobin fraction and hypertension, or to examine the impact of G1 versus G2 separately on the development of albuminuria. While these data show the association of APOL1 with albuminuria, it will be important to evaluate the association of APOL1 variants with a decline in eGFR in this and other adult cohorts. Finally, our time-to-event analysis was based on the development of a first episode albuminuria.

In summary, we have shown that the onset of glomerular injury leading to albuminuria occurs earlier than ten years of age in participants with APOL1 risk alleles, and we suggest that children with SCA should be screened for APOL1 variants to apply the principles of precision medicine by identifying a high-risk population that may benefit from earlier screening for renal damage and potentially to initiate renoprotective therapies. In the future, we aim to track participants into adulthood to 
assess how APOL1 risk alleles and other modifiers influence the progression from albuminuria to CKD to ESRD.

Rima S. Zahr, ${ }^{1 *}$ Evadnie Rampersaud, ${ }^{2 *}$ Guolian Kang, ${ }^{3}$ Mitchell J. Weiss, ${ }^{4}$ Gang Wu, ${ }^{2}$ Robert L. Davis,

Jane S. Hankins, ${ }^{4}$ Jeremie H. Estepp ${ }^{4+*}$ and Jeffrey

Lebensburger"

${ }^{*} R S Z$ and ER contributed equally to this work. **JHE and JL contributed equally as co-senior authors.

'Division of Pediatric Nephrology and Hypertension, University of Tennessee Health Science Center, Memphis, TN; ${ }^{2}$ Department of Computational Biology, St. Jude Children's Research Hospital, Memphis, TN; ${ }^{3}$ Department of Biostatistics, St. Jude Children's Research Hospital, Memphis, TN; ${ }^{4}$ Department of Hematology, St. Jude Children's Research Hospital, Memphis, TN; 'Biomedical Informatics, University of Tennessee Health Science Center, Memphis, TN and ${ }^{6}$ Division Pediatric Hematology and Oncology, University of Alabama at Birmingham, Birmingham, AL, USA

Acknowledgments: the authors thank the families and children with SCD who participated in SCRIPP.

Correspondence: JEFFREY LEBENSBURGER-

jlebensburger@peds.uab.edu doi:10.3324/haematol.2018.212779

Information on authorship, contributions, and financial \& other disclosures was provided by the authors and is available with the online version of this article at www.haematologica.org.

\section{References}

1. McPherson Yee M, Jabbar SF, Osunkwo I, et al. Chronic kidney disease and albuminuria in children with sickle cell disease. Clin J Am Soc Nephrol. 2011;6(11):2628-2633.

2. Guasch A, Navarrete J, Nass K, Zayas CF. Glomerular involvement in adults with sickle cell hemoglobinopathies: Prevalence and clinical correlates of progressive renal failure. J Am Soc Nephrol. 2006;17(8):2228-2235

3. Nielsen L, Canoui-Poitrine F, Jais JP, et al. Morbidity and mortality of sickle cell disease patients starting intermittent haemodialysis: a comparative cohort study with non- Sickle dialysis patients. Br J Haematol. 2016;174(1):148-152

4. Haymann JP, Hammoundi N, Stojanovic S, et al. Renin-angiotensin system blockade promotes a cardio-renal protection in albuminuric homozygous sickle cell patients. Br J Haematol. 2017;179(5):820-828.

5 Hou FF, Zhang X, Zhang GH, et al. Efficacy and safety of benazepril for advanced chronic renal insufficiency. $N$ Engl J Med. 2006;354(2):131-140

6. Zahr RS, Hankins JS, Kang G, et al. Hydroxyurea prevents onset and progression of albuminuria in children with sickle cell anemia. Am J Hematol. 2018;94(1):E27-E29.

7. Bartolucci P, Habibi A, Stehle T, et al. Six Months of Hydroxyurea Reduces Albuminuria in Patients with Sickle Cell Disease. J Am Soc Nephrol. 2016;27(6):1847-1853

8. Parsa A, Kao WH, Xie D, et al. APOL1 risk variants, race, and progression of chronic kidney disease. N Engl J Med. 2013;369(23):21832196.

9. Kopp JB, Nelson GW, Sampath K, et al. APOL1 genetic variants in focal segmental glomerulosclerosis and HIV-associated nephropathy. J Am Soc Nephrol. 2011;22(11):2129-2137.

10. Ashley-Koch AE, Okocha EC, Garrett ME, et al. MYH9 and APOL1 are both associated with sickle cell disease nephropathy. Br J Haematol. 2011:155(3):386-394.

11. Peralta CA, Bibbins-Domingo $\mathrm{K}$, Vittinghoff $\mathrm{E}$, et al. APOL1 Genotype and Race Differences in Incident Albuminuria and Renal Function Decline. J Am Soc Nephrol. 2016;27(3):887-893.

12. Kasembeli AN, Duarte R, Ramsay M, et al. APOL1 Risk Variants Are Strongly Associated with HIV-Associated Nephropathy in Black South Africans. J Am Soc Nephrol. 2015;26(11):2882-2890.

13. Larsen CP, Beggs ML, Saeed M, Walker PD. Apolipoprotein L1 risk variants associate with systemic lupus erythematosus-associated collapsing glomerulopathy. J Am Soc Nephrol. 2013;24(5):722-725.

14. Saraf SL, Shah BN, Zhang X, et al. APOL1, alpha-thalassemia, and BCL11A variants as a genetic risk profile for progression of chronic kidney disease in sickle cell anemia. Haematologica. 2017;102(1):e1e6.

15. Kormann R, Jannot AS, Narjoz C, et al. Roles of APOL1 G1 and G2 variants in sickle cell disease patients: kidney is the main target. $\mathrm{Br} J$ Haematol. 2017;179(2):323-335.

16. Hankins JS, Estepp JH, Hodges JR, et al. Sickle Cell Clinical Research and Intervention Program (SCCRIP): A lifespan cohort study for sickle cell disease progression from the pediatric stage into adulthood. Pediatr Blood Cancer. 2018;65(9):e27228. 